\title{
Eight New Species of Dicranocentrus and Redescriptions for $D$. thaicus and $D$. pilosus (Collembola: Entomobryidae: Orchesellinae) ${ }^{1}$
}

\author{
José A. Mari Mutt ${ }^{2}$ \\ ABSTRACT
}

Eight new species of Dicranocentrus are described: capitaneus (Peru), reunionensis (Reunion Island), indecisus (Nepal); gapudi, luzonensis, and litoreus (Philippine Islands); halophilus and gemellus (Papua New Guinea). Dicranocentrus thaicus Yosii and D. pilosus Mari Mutt are redescribed. Dicranocentrus litoreus and $D$. halophilus were collected on seashores and present several modifications apparently evolved as adaptations to this habitat: thick short claws, elongated mandibles, enlarged labral setae, and loss of the mucronal spine. These two species also have a reduced head and body chaetotaxy, very similar to that of the species of Heteromurus s, str. Eightynine figures complement the descriptions.

\section{INTRODUCTION}

During a recent visit to the laboratories of Drs. Judith Najt, Paul Cassagnau, and Louis Deharveng, I gathered a large number of Orchesellini and Heteromurini that were collected by them or forwarded by various entomologists. The material contains eight new species of $D i$ cranocentrus and two previously named forms that are redescribed below. The species of Heteromurus belong to the subgenus Alloscopus.

The holotype of Dicranocentrus capitaneus is deposited in the National Museum of Natural History, Paris, and the holotype of D. halophilus is in the Australian National Insect Collection, Canberra. The other specimens remain in my collection.

Morphological abbreviations used throughout this paper are as follows: Ant. 2, Th. 2, Abd. 2, etc. = second antennal segment, second thoracic segment, etc.

\section{DESCRIPTIONS}

\section{Dicranocentrus capitaneus NEW SPECIES}

Maximum length $5.5 \mathrm{~mm}$. Distribution of violet pigment as in figure 1; 2 dorsolateral stripes extend from posterior margin of Th. 2 to posterior margin of Abd. 5. Head with band of pigment between eyes and antennal bases, and around mouth cone with most intensity on clypeal region.

${ }^{1}$ Manuscript submitted to Editorial Board June 4, 1984.

${ }^{2}$ Entomological Research Laboratory, University of Puerto Rico, Mayagüez, Puerto Rico 00708. My sincere thanks go to Drs. J. Najt, P. Cassagnau and L. Deharveng. They not only trusted me with part of their collections but also kindly provided transportation, housing, excellent food and hours of translating Spanish and English into French. 
Ant. 5 intensely pigmented proximally, then without pigment until distal half, which is lightly colored. Ant. 6 missing.

Head macrochaetotaxy as in figure 2. Interocular chaetotaxy (fig. 5) of 1 outer seta, 3-4 inner setae and $4-5$ scales. Margin of labrum with 4 broad, oval, upturned papillae, the outer pair of which is considerably larger (fig. 8). Setae of maxillary palp similar in shape but subapical seta longer (fig. 7). Differentiated seta of outer labial papilla placed far back; its apex does not reach apex of the papilla (fig. 6). Posterior labial row internal to seta e with 1-2 smooth setae, 7-8 ciliated setae, and 5-8 scales; $1_{1}$ smooth or ciliated, $1_{2}$ smooth. Setae of venter of head smooth except for 2-3 large ciliated setae near median groove close to posterior margin of head (cf. fig. 19).

Trochanteral organ of about 100 slender setae. Inner margin of tibiotarsi with many erect, finely ciliated setae that under low magnification seem smooth. Unguis internally tridentate or quadridentate (fig. 4), both types not in same specimen. Outer margin of unguis with 3 large basal teeth. Unguiculus with an outer tooth, tenent hair clavate.

Body macrochaetotaxy as in figure 3 . Tenaculum with 1 seta. Dorsum of manubrium with many scales and without smooth setae. Inner margin of dentes with 3-4 rows of spines; outer 2 rows distinct, with 18-21 and 8-18 spines, respectively. Inner 2 rows irregular, with about 20 spines total.

\section{Diagnosis}

Dicranocentrus capitaneus is close to three species known only from Peru (surroundings of Cuzco and Machu Picchu): D. schoetti Mari Mutt 1979, D. orellanae Jacquemart 1980 and D. edicitae Jacquemart 1980. It can be distinguished from them, and from all other Dicranocentrus, by the color pattern; it is at least $1.2 \mathrm{~mm}$ longer than any other species. From $D$. schoetti it differs also by the chaetotaxy of Abds. 3 and 4. From $D$. orellanae, the new species may be further separated by the number of macrochaetae on the posterior half of the head and by the chaetotaxy of Th. 2 and Abd. 3. From D. edicitae it may be distinguished by the number of macrochaetae on the posterior half of the head and by the chaetotaxy of Th. 3 and Abds. 1, 3 and 4.

\section{Comments}

Figure 1 gives the distribution of pigment for one specimen. A light specimen has only faint indications of the dorsolateral stripes whereas a third specimen is much darker and with even more conspicuous stripes.

Material Examined. Peru, Contumaza, 2,850 m, ii.1942, W. Weyrsuiz (?), holotype and 2 paratypes ( 1 on slide). 


\section{Dicranocentrus reunionensis NEW SPECIES}

Maximum length $3.2 \mathrm{~mm}$. Distribution of violet pigment as in figure 9; body, most of head, collophore and furcula unpigmented. Pigment on head restricted to eye patches and a small but distinct spot between bases of antennae. Ratio length of antenna/length of specimen $=0.89$, antennae/length of head $=4.4$, Ant. 6/Ant. $5=0.5$. Apex of Ant. 6 with very small conical pin seta (fig. 14), apparently absent in some specimens.

Macrochaetotaxy of anterior half of head as in figure 10, An group with 10-12 setae. Posterior half of head without macrochaetae. Interocular chaetotaxy (fig. 13) of 1-2 outer setae, 3-4 inner setae (4 seen only on 1 side of 1 specimen) and 4-8 scales. Outer pair of labral papillae broad and upturned, inner pair thumblike (fig. 18). Setae of maxillary palp similar in shape but apical seta longer (fig. 17). Differentiated seta of outer labial papilla with its apex approaching apex of the papilla (fig. 12). Posterior labial row internal to seta e with 1-2 smooth setae (2 seen only on 1 side of 1 specimen), 1-4 ciliated setae, and 5-8 scales (fig. 16); $1_{1}$ and $1_{2}$ smooth. Behind postlabial quadrangle a pair of long finely ciliated setae on each side of median groove (fig. 19). Setae immediately behind labium smooth; setae of posterior half of head minutely ciliated.

Trochanteral organ of up to 55 slender setae. Tibiotarsi without smooth setae. Unguis internally tridentate or quadridentate (fig. 11), both types in some specimens. Unguiculus with an outer tooth. Tenent hair clavate, with apex frequently (59\% of legs) bent up, giving the impression that the hair is inserted upside down.

Body macrochaetotaxy as in figure 15 . Tenaculum with 1 seta. Dorsum of manubrium with many scales and no smooth setae. Dental lobe with a macrochaeta-like seta and 1-2 similar but shorter and thinner setae. Dens with outer row of 6-13 spines and 33-67 spines arranged in 3-4 inner rows (fig. 20). Male genital plate multisetaceous, with about 45 smooth setae forming 3 concentric rows, inner row distinct, outer rows irregular.

\section{Diagnosis}

The only other species with spines on the outer margin of the dentes and without macrochaetae on the posterior half of the head are $D$. spinosus Prabhoo 1971 (southern India) and D. biseriatus Mari Mutt 1981a (Haiti). From the former, the new species may be distinguished by the relative lengths of Ants. 5 and 6, lanceolate tenent hairs in spinosus, number of spines on inner margin of dentes, and details of the chaetotaxy of Th. 2 and Abd. 4. The new species may be differentiated from $D$. biseriatus by the pigmentation of the body, relative lengths of Ants. 5 and 6 , presence of a large pin seta in biseriatus, presence of ciliated setae 
on the labial triangle of reunionensis, number and arrangement of spines on inner margin of dentes, and by the chaetotaxy of Abd. 4 .

\section{Comments}

One metathoracic leg has two tenent hairs, both with upturned apex, and lacks the trochanter. The femur is longer than usual, and its basal portion has the setae of the trochanteral organ in an irregular arrangement.

The setae signalled by arrows in figure 15 are reduced on some specimens. If these setae were to disappear the pattern produced would be very similar or identical to that of other species of the genus (e.g. $D$. marias).

\section{Material examined}

I have studied in detail 12 specimens out of 101 that constitute the type series. All the material was collected on Reunion Island, Bebour Plateau, $1300 \mathrm{~m}$, by J. Etienne on the following dates: 20.xi.1975 (includes the holotype), 27.xi.1975, 30.xii.1975, and 15.vi.1976. The specimens were collected from mosses growing on rocks, near the base of trees and on the trees.

\section{Dicranocentrus thaicus Yosii}

Dicranocentrus thaicus Yosii 1961: 179-181 (orig. descr.) Salmon 1964: 478 (mention). Mari Mutt 1979: 20, 70 (key, diagnosis).

Maximum length $4.3 \mathrm{~mm}$. Distribution of violet pigment as in $D$. indecisus. Ant. 6 missing, ratio Ant. 6/ Ant. 5 (from Yosii 1961: 180, fig. $\mathrm{B})=0.34$. Apex of regenerated Ant. 5 with large 2 or 3 -pointed pin seta (types C-E in Christiansen and Bellinger 1980: 794).

Head macrochaetotaxy as in figure 21. Interocular chaetotaxy (fig. 23) of 1 outer seta and 3-4 inner setae. Labral papillae hooklike (fig. 27). Setae of maxillary palp similar in length and shape (fig. 26). Differentiated seta of outer labial papilla placed far back on its papilla (fig. 25). Posterior labial row internal to seta e (fig. 28) with 1 smooth and 6-10 ciliated setae; $1_{1}$ smooth or ciliated, $1_{2}$ smooth. Behind postlabial quadrangle, near posterior margin of head, 3-4 ciliated setae on each side of median groove (see comments). Parallel to posterior margin of labium, a row of about 12 long smooth setae alternated with short unilaterally ciliated setae; behind this row more smooth setae and unilaterally ciliated setae, posterior half of head only with finely ciliated setae.

Trochanteral organ of 60-95 slender setae. Tibiotarsi without smooth setae but with several thick, erect, finely ciliated setae. Unguis internally tridentate or quadridentate (fig. 22), both types in some specimens. Outer 
margin of unguis with 3 large teeth. Unguiculus with an outer tooth, tenent hair lanceolate or clavate (clavate only in 1 leg of 1 specimen).

Body macrochaetotaxy as in figure 24. Tenaculum with 1 seta. Dorsum of manubrium without smooth setae or scales. Dentes without smooth setae or spines, dental lobe with several macrochaeta-like setae.

\section{Diagnosis}

Only three other species of the genus, all from Nepal, have 6 macrochaetae on each side of Abd. 1 and lack dental spines: D. pilosus Mari Mutt (Mari Mutt and Bhattacharjee 1980), D. deharvengi Mari Mutt 1981b and D. indecisus described later in this paper. D. thaicus can be readily distinguished from $D$. pilosus, a most peculiar species, by pigmentation, head and body chaetotaxy and claw structure. D. thaicus may be differentiated from the other two species by the chaetotaxy of Th. 2, Th. 3, Abd. 3 and Abd. 4.

\section{Comments}

The above description differs from the original in only one detail. Yosii reports (p. 180, fig. A) the presence of 2 macrochaetae on the inner middle portion of Th. 2, where I have invariably found 1 macrochaeta. On both sides of the ventral groove, near the posterior margin of the head, is a group of large ciliated setae varying in number as follows (in parentheses the number of specimens with that number of setae): $3+2$ (2), $3+3(5), 3+4(2), 4+4$ (1). When the same number of setae is present on both sides of the head their position will frequently vary (fig. $46-48)$.

\section{Material Examined}

Thailand, Doi Inthanon, 2,000-2,500 m, 2.i.1981, leaf litter, humid mosses and rotten tree trunks, L. Deharveng and A. Gouze, 126 specimens (11 on slides). As preceding, but collected 9.i.1981, 41 specimens (2 on slides). Doi Chiang Dao, 2,000 m, 21.xii.1980, leaf litter and humus, L. Deharveng and A. Gouze, 18 specimens (2 on slides).

\section{Dicranocentrus indecisus NEW SPECIES}

Maximum length $3.2 \mathrm{~mm}$. Distribution of violet pigment as in figure 29. Ant 6 missing. Head macrochaetotaxy and interocular chaetotaxy as in figures 30 and 32, respectively. Labral papillae hooklike. Setae of maxillary palp (fig. 33) similar in length and shape. Differentiated seta of outer labial papilla placed far back on its papilla (fig. 35). Posterior labial row internal to seta e with 1-3 smooth and 4-7 ciliated setae; $1_{1}$ smooth or ciliated; $1_{2}$ smooth. Behind postlabial quadrangle, near posterior margin of head, 3-4 ciliated setae on each side of median groove. 
Parallel to posterior margin of labium, a row of 5-8 smooth setae alternating with ciliated setae; behind this row 1-5 smooth setae, posterior half of head only with finely ciliated setae.

Trochanteral organ with 50-61 slender setae. Tibiotarsi without smooth setae. Unguis quadridentate (fig. 34), unguiculus with an outer tooth, tenent hair has fallen off from all legs.

Body macrochaetotaxy as in figure 31 . Tenaculum with 1 seta. Dorsum of manubrium with many scales and setae, type of seta cannot be determined. Dental lobe with a macrochaeta-like seta, dentes without spines.

\section{Diagnosis}

This species is very similar to $D$. deharvengi Mari Mutt 1981b. They differ only in the presence of an extra macrochaeta on Th. 3 of indecisus, absence of smooth setae on the labial triangle of deharvengi, and absence or presence of very few smooth setae on the venter of the head of deharvengi. The head and body chaetotaxy (except Th. 3) is identical in both species; this I have verified by the study of the paratypes of deharvengi deposited in my collection.

\section{Material examined}

Nepal. Pisang, northeast of Annapurna Himal, 2,850 m, on mosses, 3.x.1977, L. Deharveng, holotype. As preceding, but at 3,000 m, under Norway spruce, 5 paratypes ( 2 on slides).

\section{Dicranocentrus pilosus Mari Mutt}

Dicranocentrus pilosus Mari Mutt, in Mari Mutt and Bhattacharjee 1980: 168, 1970.

Maximum length $2.3 \mathrm{~mm}$. Distribution of violet pigment as in figure 36 , outer margin of tibiotarsi intensely pigmented, rest of segment pale. Ratio length of antenna/length of specimen $=0.62$; antenna/length of head $=2.93$; Ant. $6 /$ Ant. $5=1.35$. Apex of Ant. 6 with large 3 -pointed (type D) pin seta.

Head macrochaetotaxy as in figure $42,8 \mathrm{~S}$ setae and Ps present. Interocular chaetotaxy (fig. 39) of 1 outer seta and 5-6 inner setae. Setae of first 2 labral rows considerably thicker than setae of third row. Labral papillae (fig. 41) hooklike and thicker than in all other species with this type of papilla. Apical seta of maxillary palp slightly longer than subapical seta (fig. 44). Differentiated seta of outer labial papilla placed far back on its papilla (fig. 45). Posterior labial row internal to seta e with 0-1 smooth and 7-14 ciliated setae; $\mathrm{L}_{1}$ ciliated, $1_{2}$ smooth. Behind postlabial 
quadrangle, near posterior margin of head, $2-4$ ciliated setae on each side of median groove, all setae of venter of head ciliated.

Trochanteral organ of 45-80 slender setae. Tibiotarsi without smooth setae, with several thick, outstanding, ciliated setae (fig. 37). Unguis (fig. 38) very long, inner lamellae with 2 basal rounded lobes, meeting distally where a small tooth is sometimes formed. Unguiculus long, with very small outer tooth and inner projection caused by junction of 2 lamellae. Tenent hair lanceolate, very short.

Body macrochaetotaxy as in figure 43 . Tenaculum with 1 seta. Dorsum of manubrium with very few (1-4) scales and no smooth setae. Dental lobe with a macrochaeta-like seta, dentes without spines. Mucro (fig. 40) elongated. Male genital plate multisetaceous, with 22 setae arranged in 2 rows.

\section{Diagnosis}

Pigmentation, chaetotaxy, and claw structure readily distinguish this species from all other members of the genus.

\section{Comments}

The seta signalled by an arrow in Fig. 42 is absent in one specimen and in another it is present in the same position but on the left side of the head.

\section{Material examined}

Nepal, Manang, north of Annapurna Himal, 3,850 m, on very wet mosses, 1.x.1977, L. Deharveng, 5 specimens (3 on slides).

\section{Dicranocentrus gapudi NEW SPECIES}

Maximum length $3.2 \mathrm{~mm}$. Distribution of violet pigment as in $D$. indecisus. Ratio length of antenna/length of specimen $=0.77$; antenna/ length of head $=3.96$; Ant. $6 /$ Ant. $5=0.51$. Apex of Ant. 6 without pin seta. Head macrochaetotaxy and interocular chaetotaxy as in figures 49 and 53 respectively. Labral papillae and differentiated seta of outer labial papilla as in $D$. thaicus. Subapical seta of maxillary palp much thicker than apical (fig. 54). Posterior labial row internal to seta e with 6-11 smooth and 1-5 ciliated setae, $1_{1}$ and $1_{2}$ smooth. Behind postlabial quadrangle, near posterior margin of head, 2-4 lightly ciliated setae on both sides of median groove. Parallel to posterior margin of labium a row of about 8 smooth setae, posterior to this row another series of similar setae. Towards posterior margin of head, setae become shorter and very finely ciliated, ciliations visible only at over $1000 \times$. 


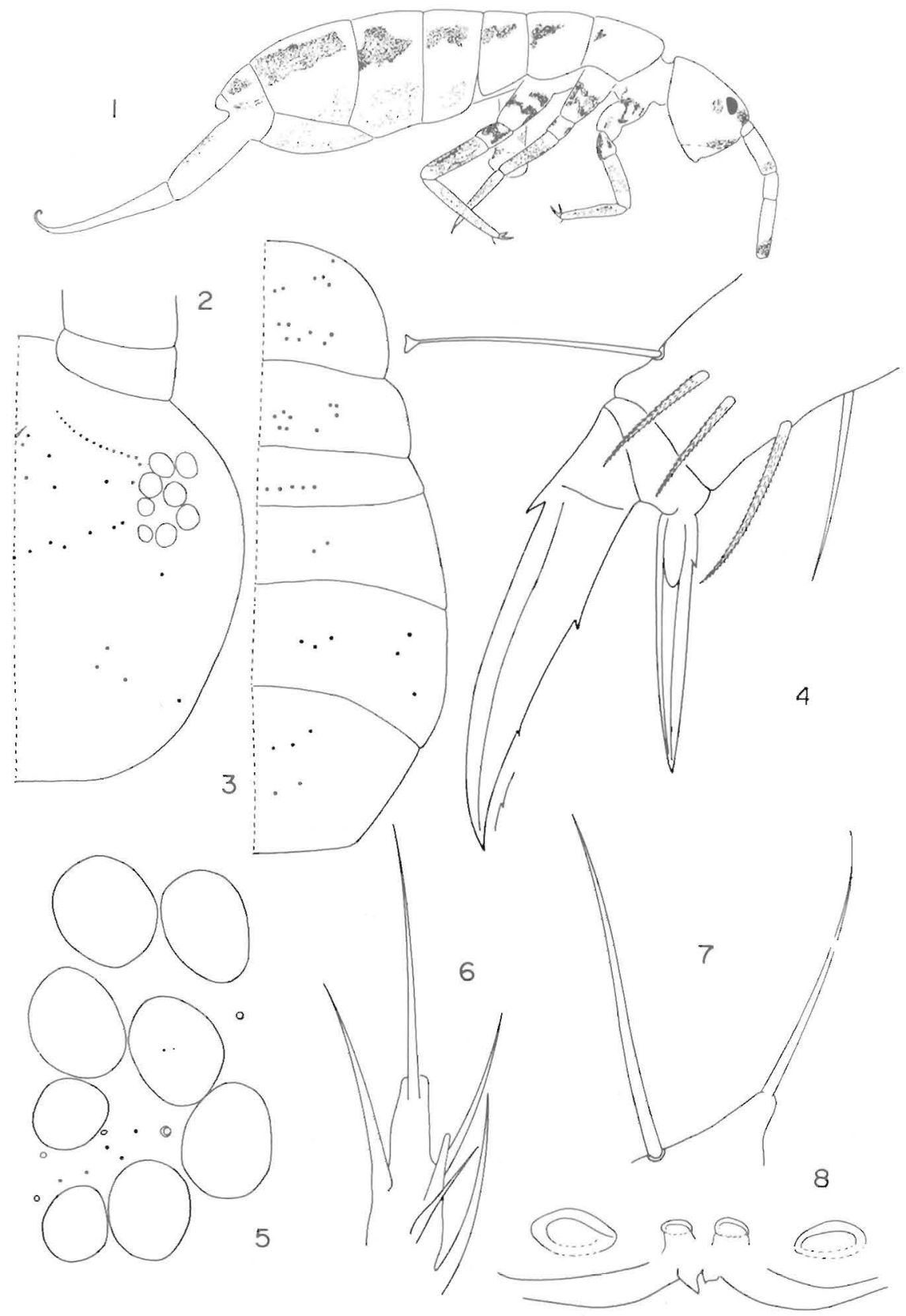

Plate I (Fig. 1-8).-D. capitaneus. 1. Distribution of violet pigment. 2. Head macrochaetotaxy. 3. Body macrochaetotaxy. 4. Metathoracic claws. 5. Interocular chaetotaxy; dots represent insertions of scales, circles represent setae. 6. Outer labial papilla. 7. Maxillary palp. 8. Labral papillae. 


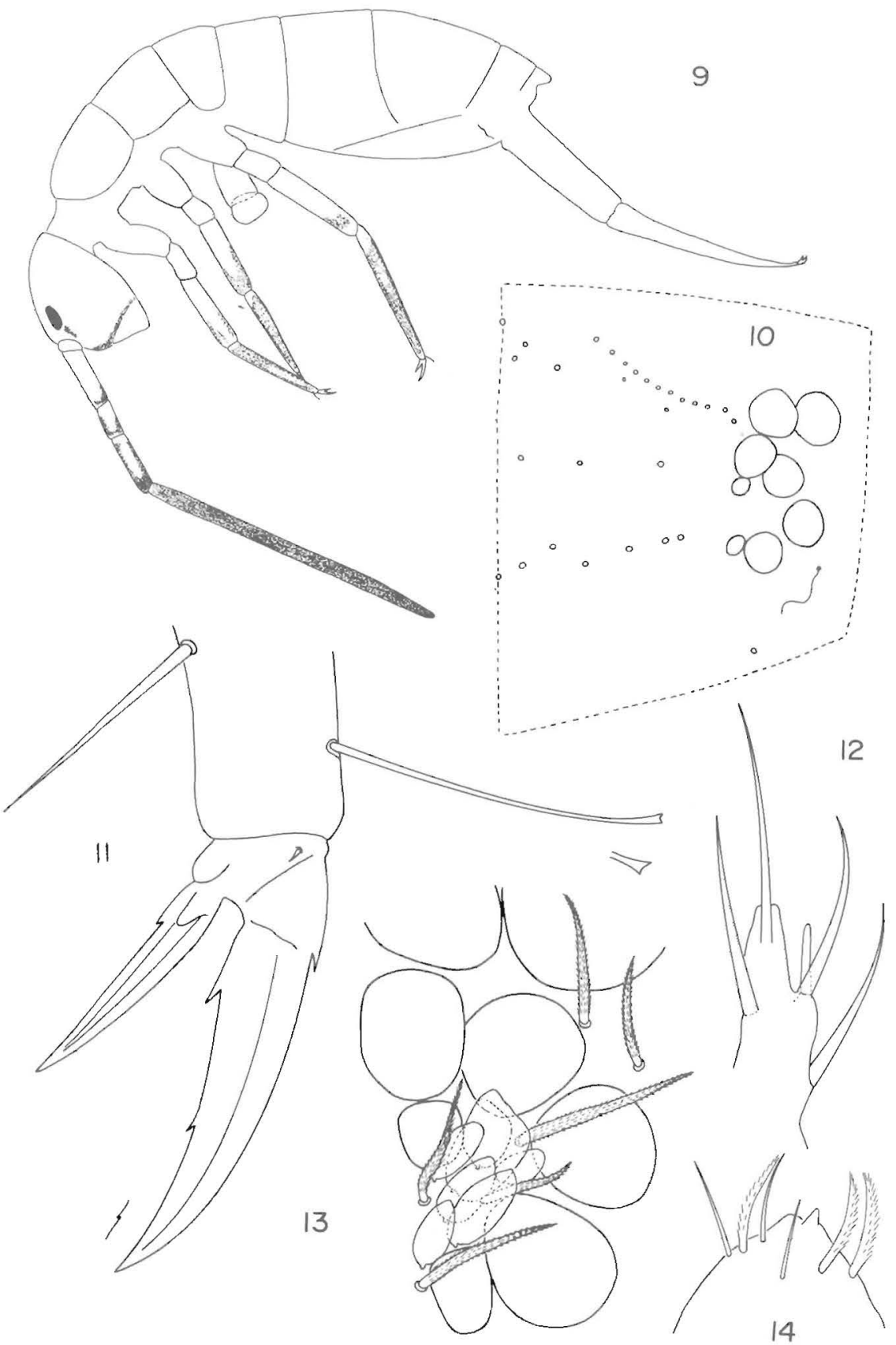

Plate II (Fig. 9-14).-D. reunionensis. 9. Distribution of violet pigment. 10. Head macrochaetotaxy. 11. Metathoracic claws. 12. Outer labial papilla. 13. Interocular chaetotaxy. 14. Apex of Ant. 6. 

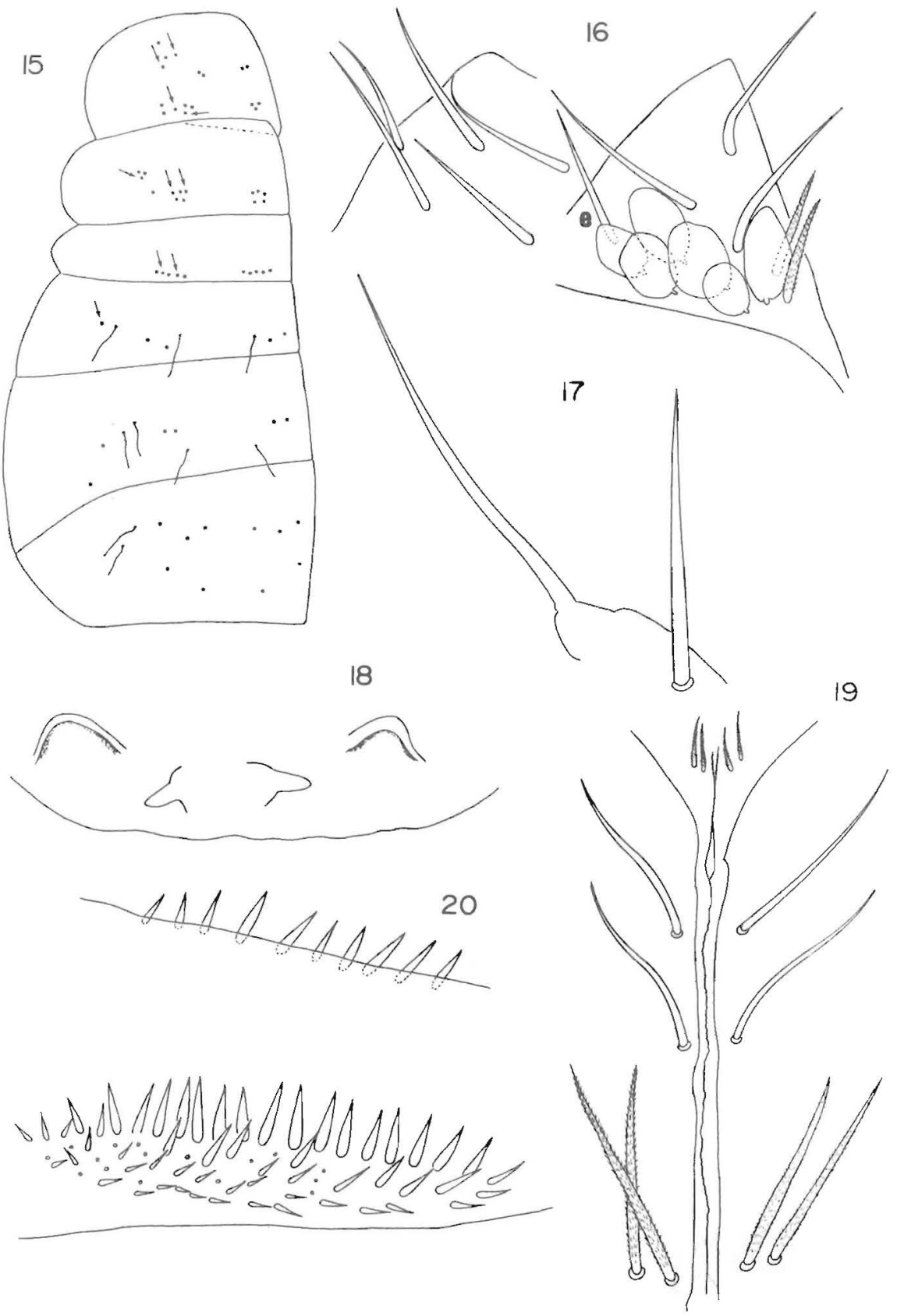

Plate III (Fig. 15-20), - D. reunionenesis. 15. Body macrochaetotaxy, setae with arrows are shorter on some specimens. 16. Labial chaetotaxy. 17. Maxillary palp. 18. Labral papillae. 19. Setae along median groove of head. 20. Dental spines. 
VOL. LXIX, NO. 3, JULY, 1985

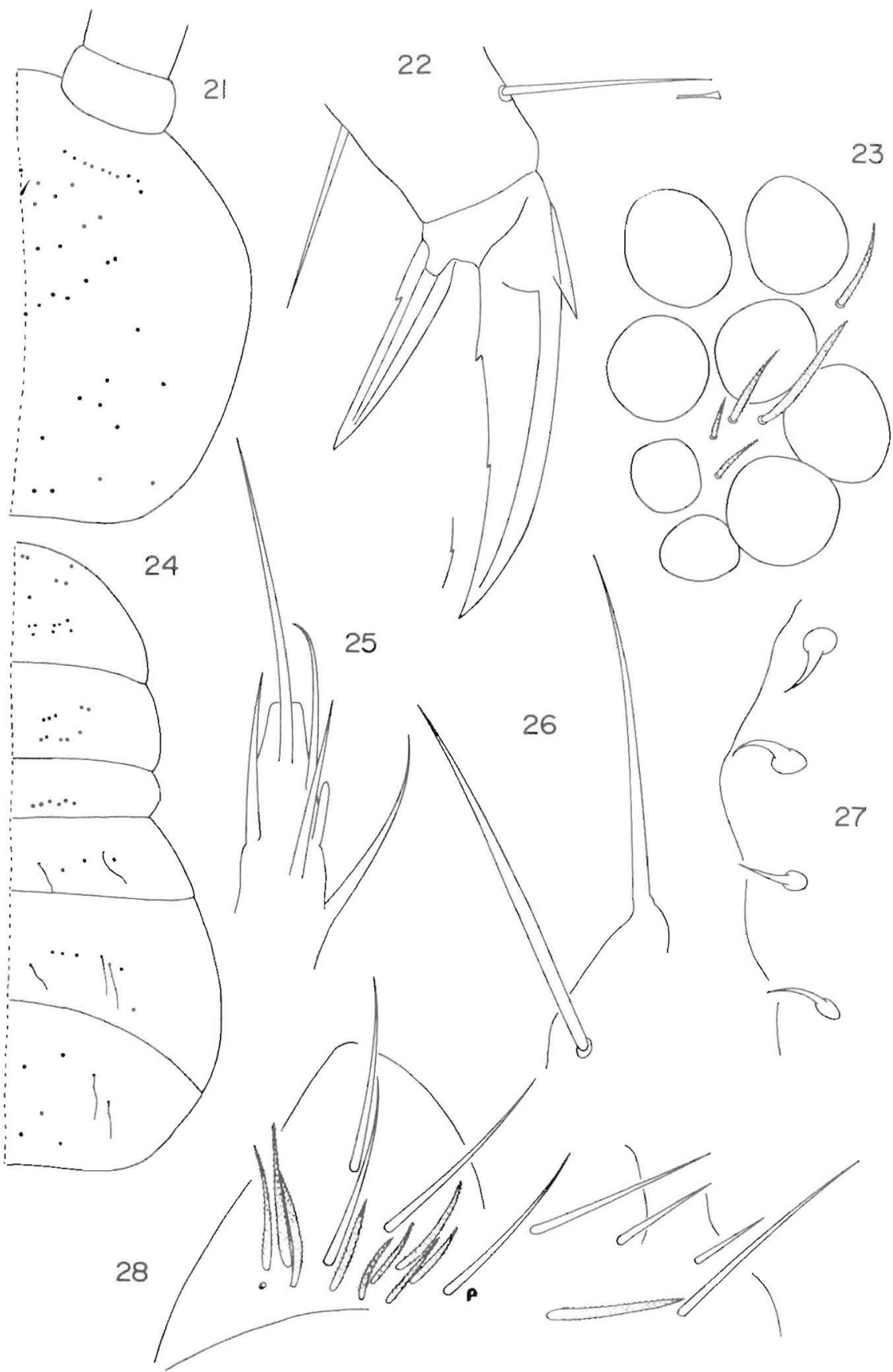

Plate IV (Fig. 21-28).-D. thaicus. 21. Head macrochaetotaxy. 22. Metathoracic claws. 23. Interocular chaetotaxy. 24. Body macrochaetotaxy. 25. Outer labial papilla. 26. Maxillary palp. 27. Labral papillae. 28. Labial chaetotaxy. 


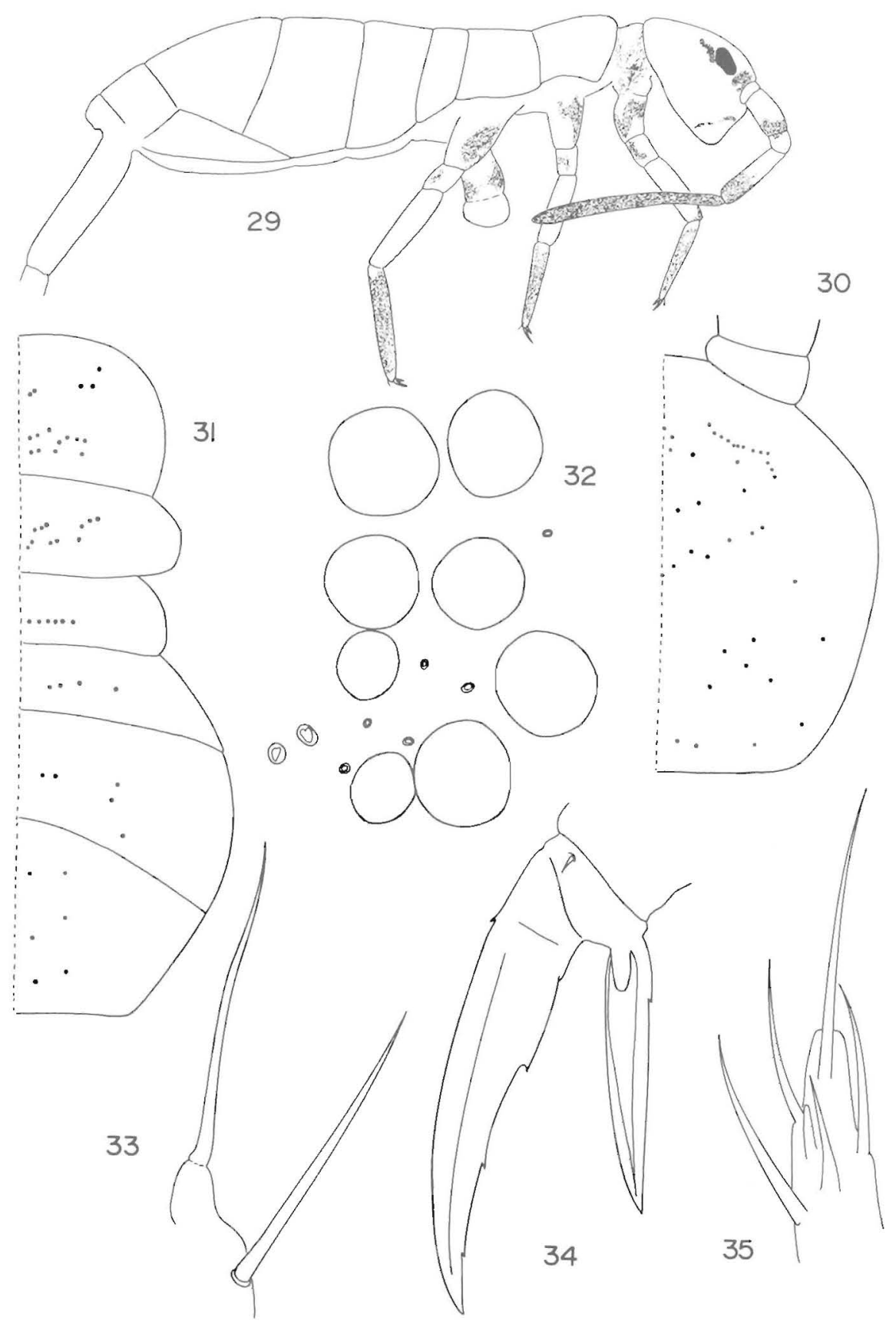

Plate V (Fig. 29-35).-D. indecisus, 29. Distribution of violet pigment. 30. Head macrochaetotaxy. 31. Body macrochaetotaxy. 32. Interocular chaetotaxy, the 2 large insertions on the left belong to macrochaetae $S_{6}$ and $S_{7}$. 33. Maxillary palp. 34. Metathoracic claws. 35 . Outer labial papilla. 


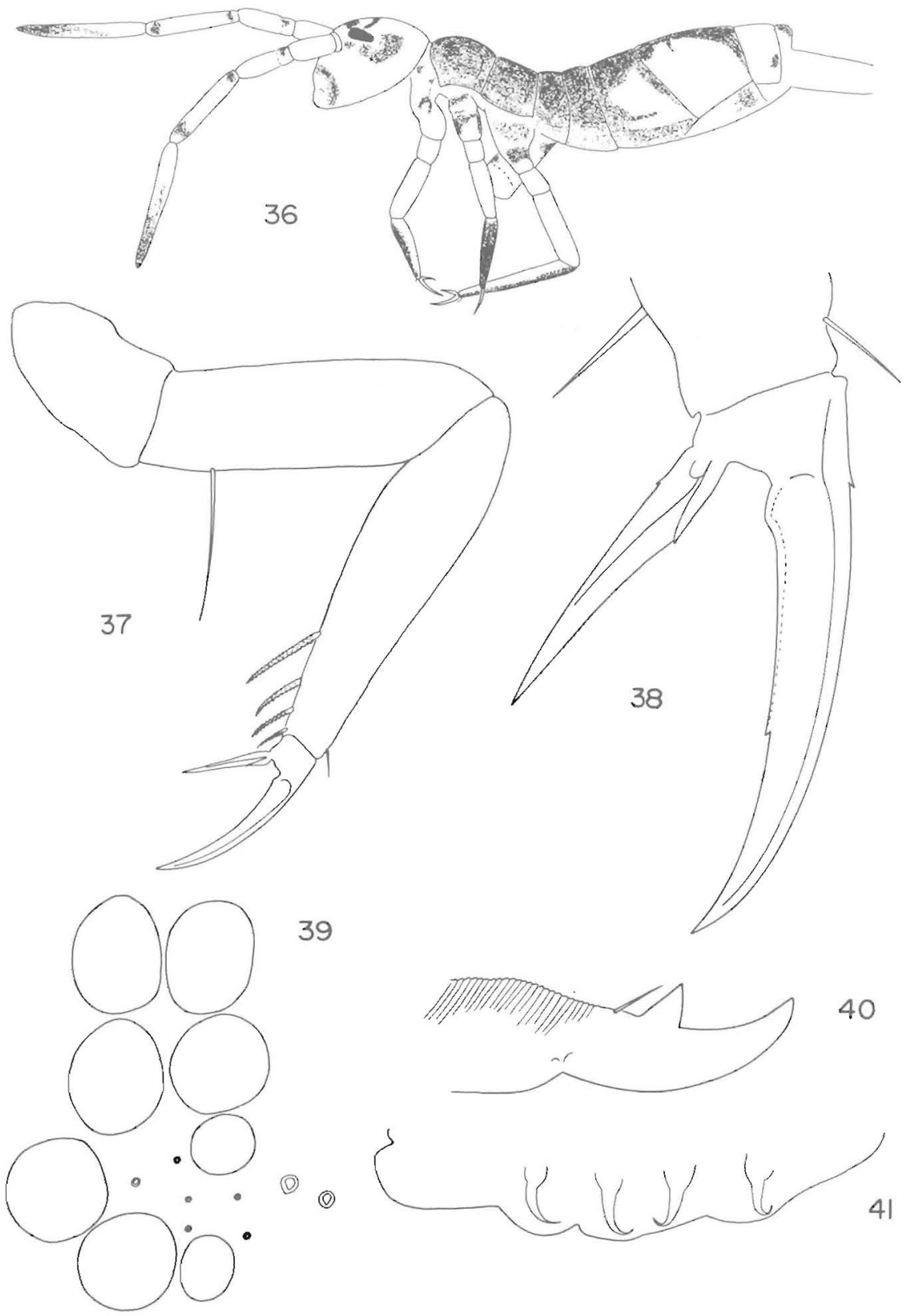

Plate VI (Fig. 36-41).-D. pilosus. 36. Distribution of violet pigment. 37. Prothoracic leg. 38. Metathoracic claws. 39. Interocular chaetotaxy, the 2 large insertions on the right belong to macrochaetae $S_{7}$ and $S_{8}$. 40. Mucro. 41. Labral papillae. 

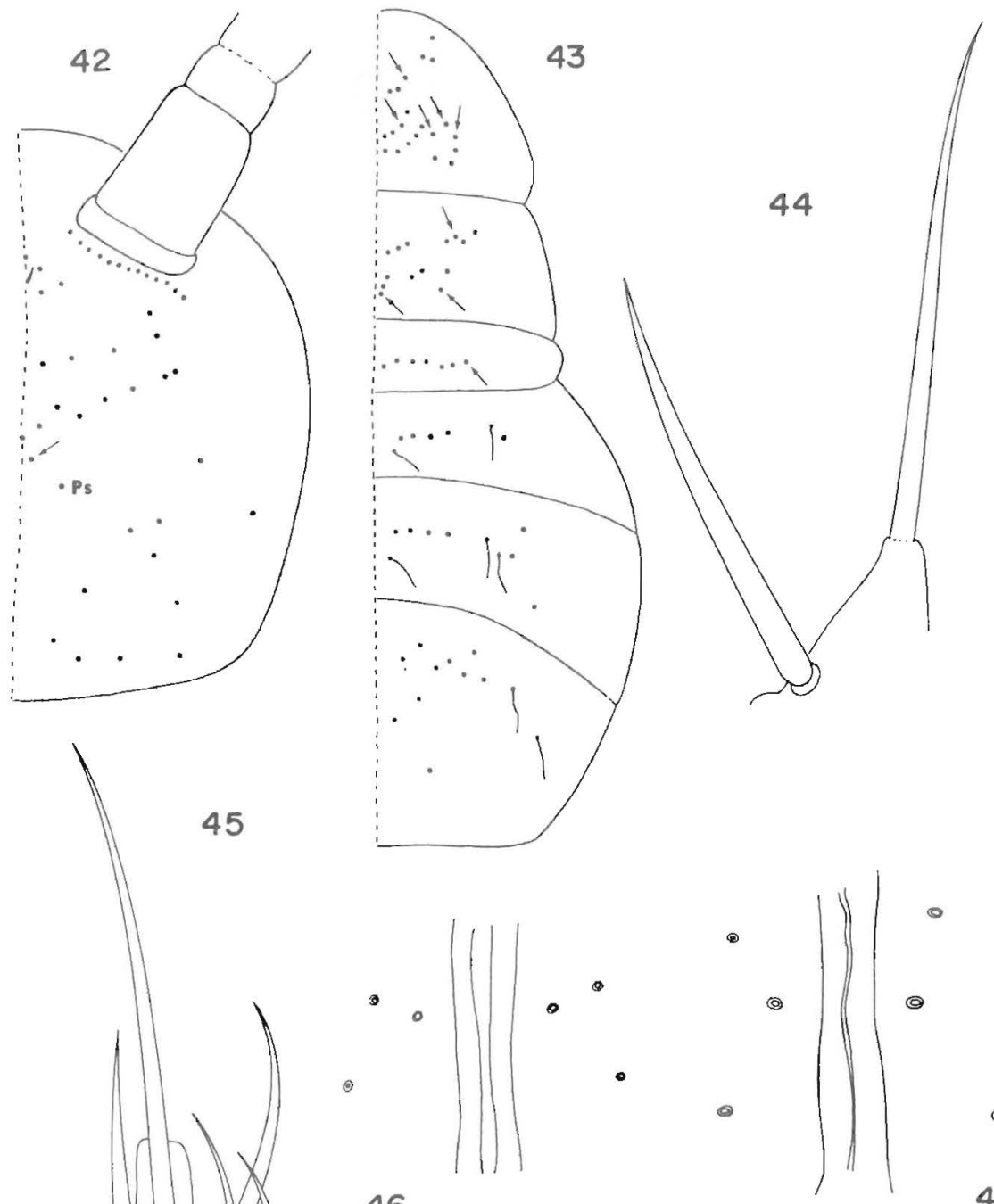

(9)

47

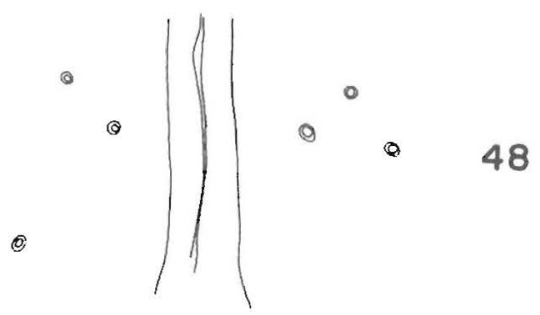

Plate VII (Fig. 42-48).-Fig. 42-45. D. pilosus. 42. Head macrochaetotaxy, Ps = postsutural seta. 43. Body macrochaetotaxy, setae with arrows are absent in some specimens. 44. Maxillary palp. 45. Outer labial papilla. 46-48. D. thaicus. Various arrangements of $3+3$ ciliated setae on posterior ventral side of head. 


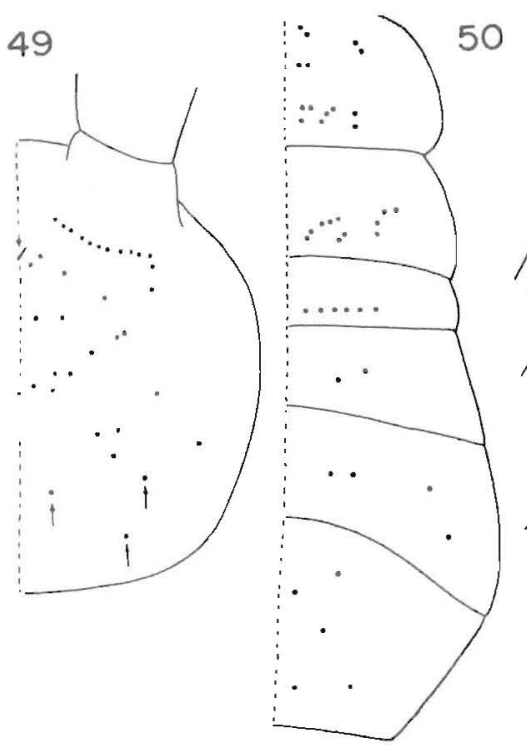

52
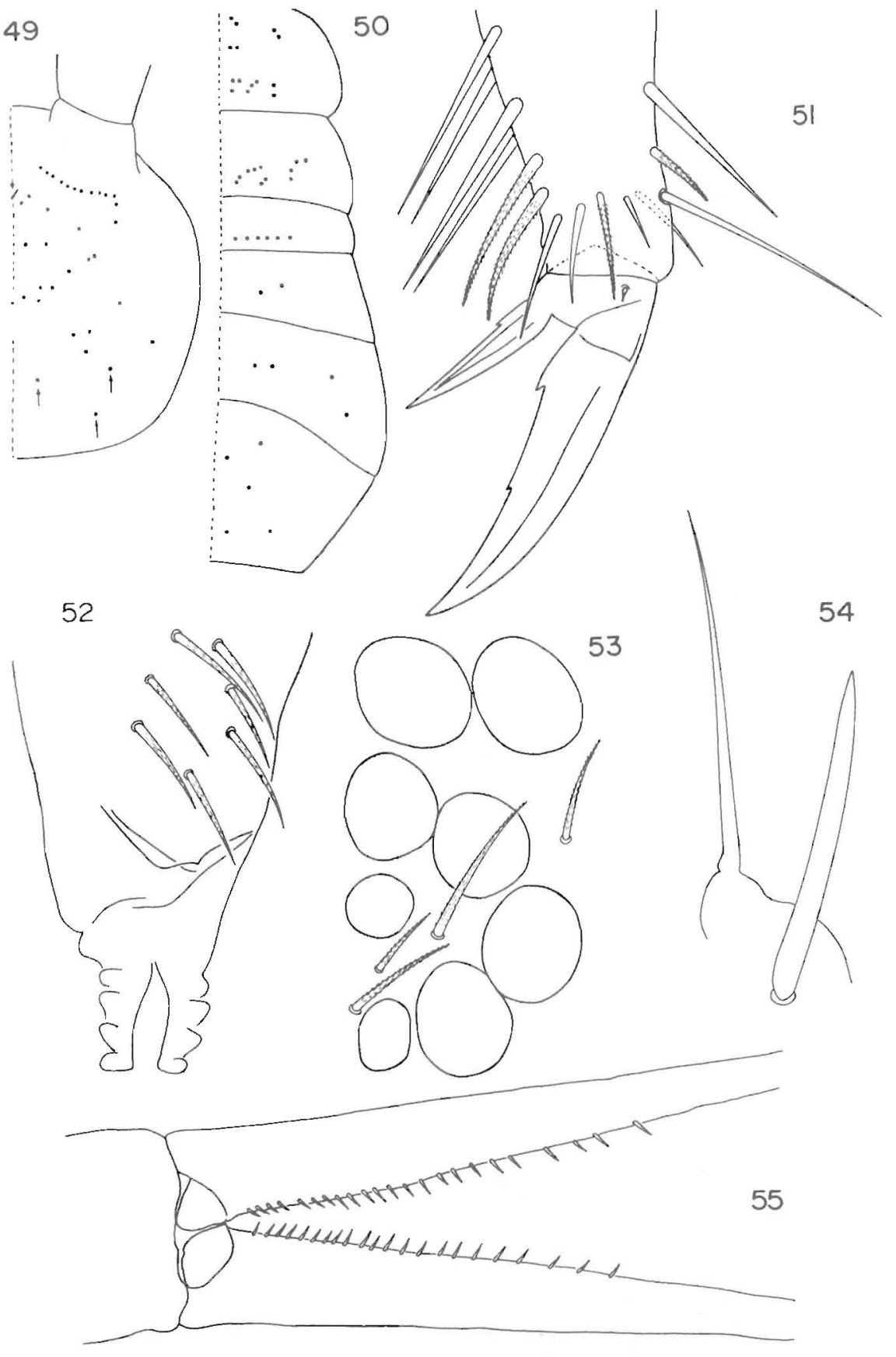

Plate VIII (Fig. 49-55) - D. gapudi. 49. Head macrochaetotaxy, setae with arrows are absent in D. luzonensis. 50. Body macrochaetotaxy. 51. Metathoracic claws. 52. Tenaculum. 53. Interocular chaetotaxy. 54. Maxillary palp. 55. Arrangement of dental spines. 


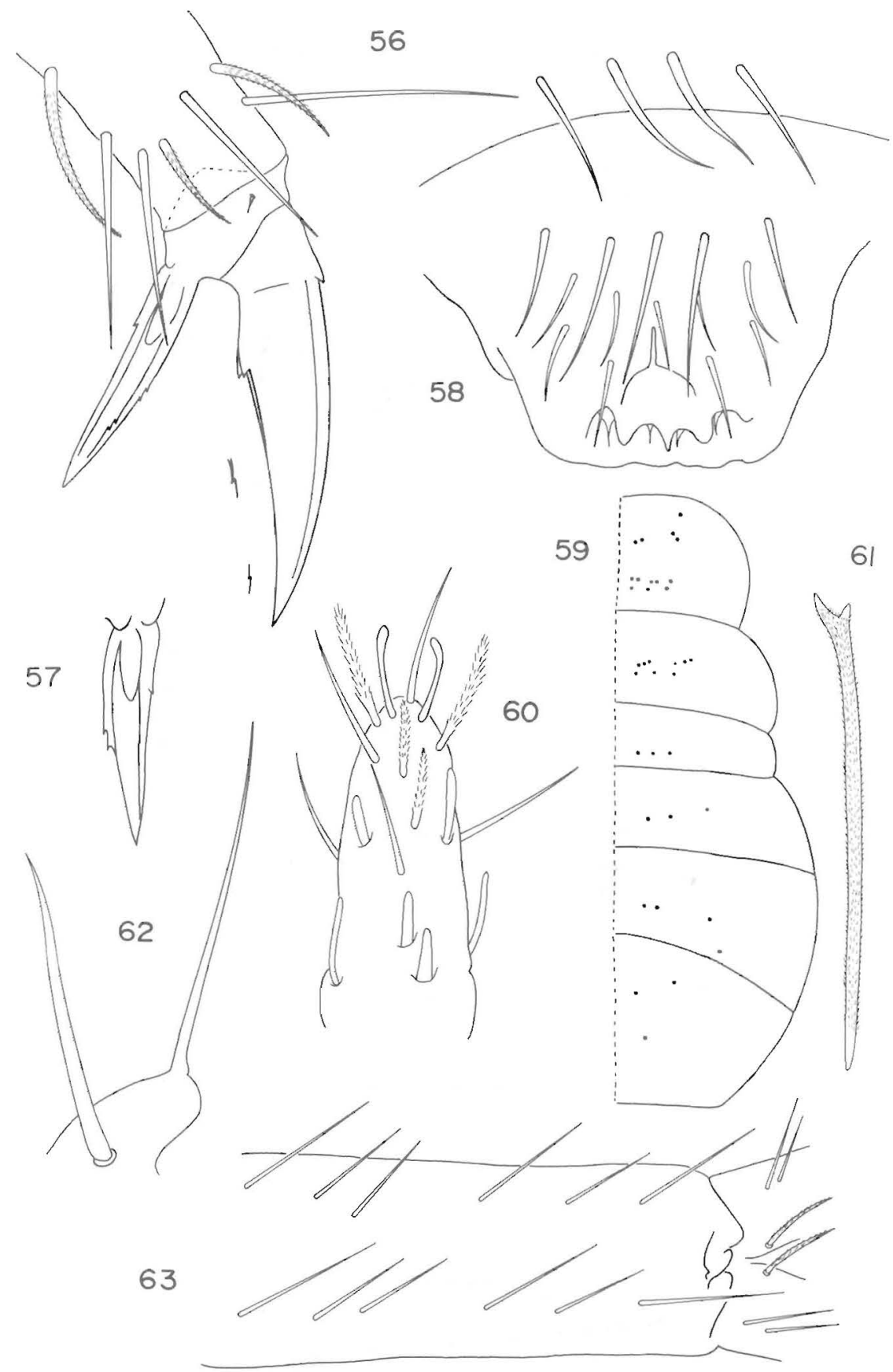

Plate IX (Fig. 56-63).-D. luzonensis. 56. Metathoracic claws. 57. Prothoracic unguiculus. 58. Labrum. 59. Body macrochaetotaxy. 60. Apex of Ant. 6. 61. Large body macrochaeta. 62. Maxillary palp. 63. Distribution of smooth setae on dorsum of manubrium and proximal portion of dentes. 


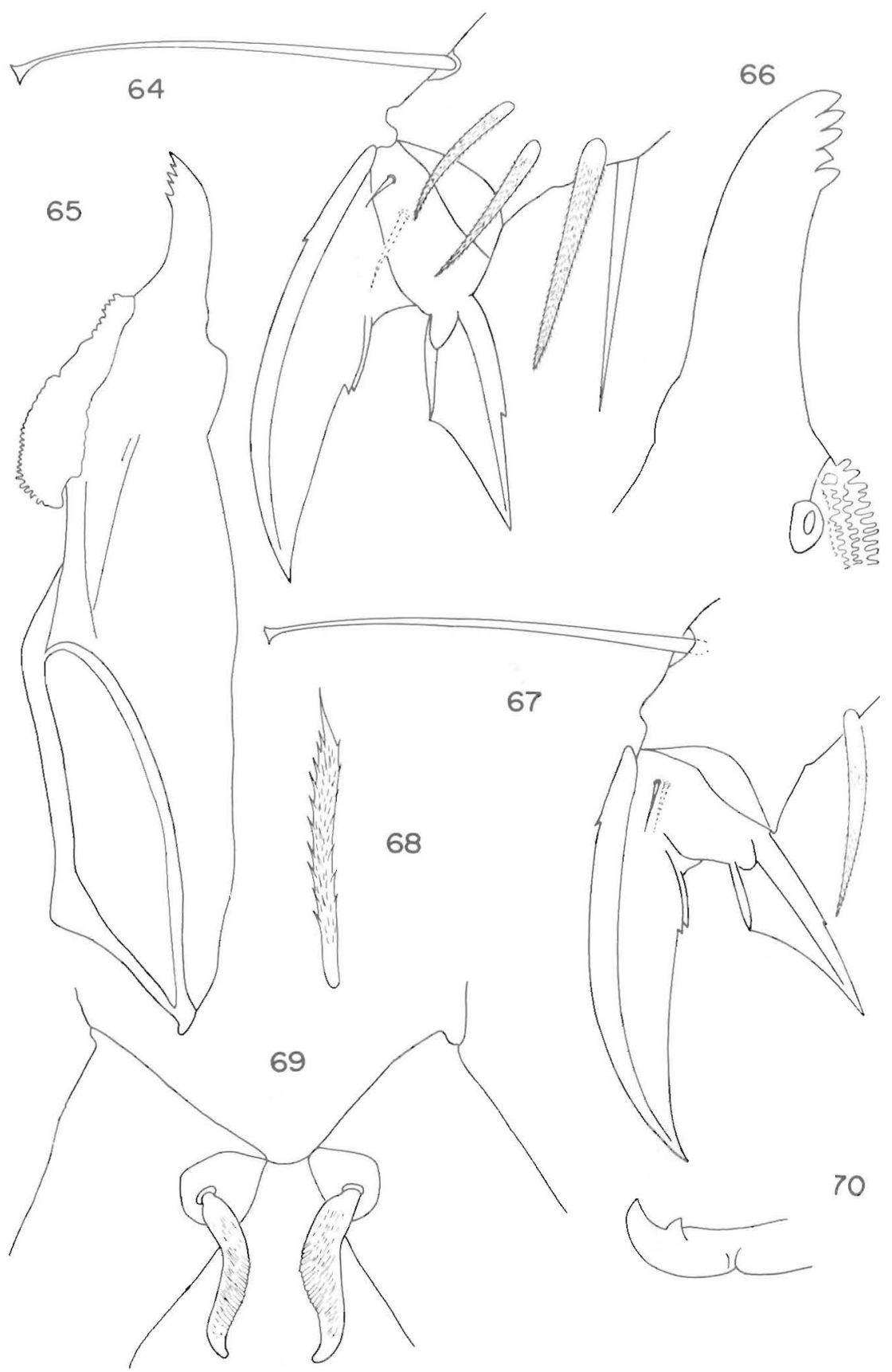

Plate X (Fig. 64-70).-D. litoreus. 64. Metathoracic claws. 65. Right mandible. 66. Head of left mandible. 67. Prothoracic claws. 68. Large manubrial seta. 69. S-shaped setae of dental lobe. 70. Mucro. 

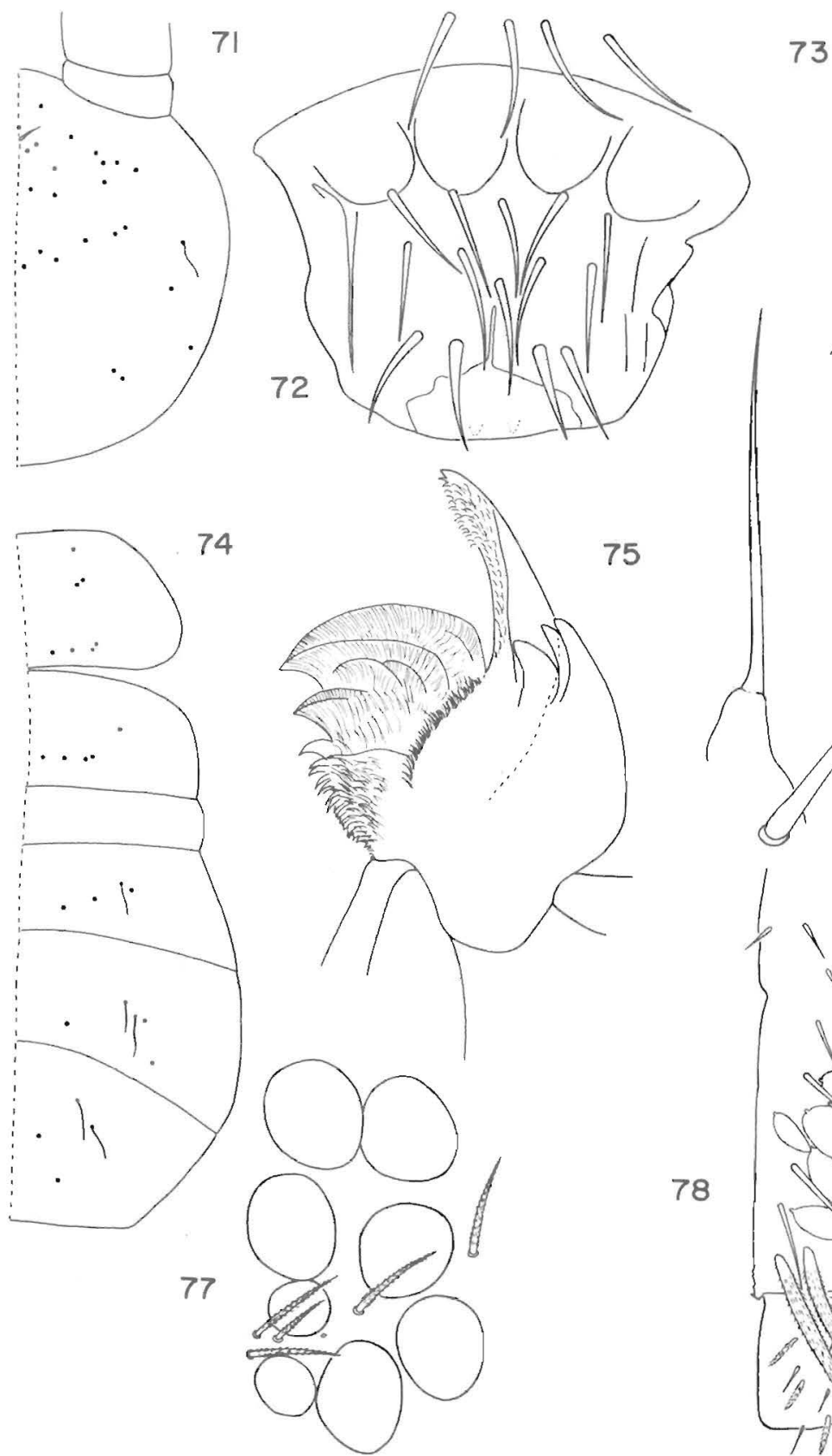

5

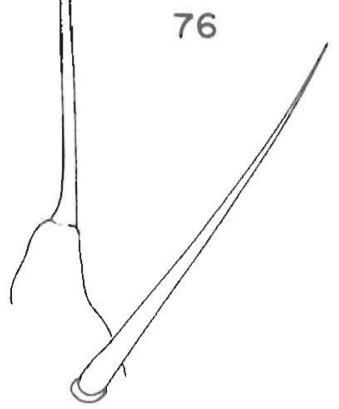

78

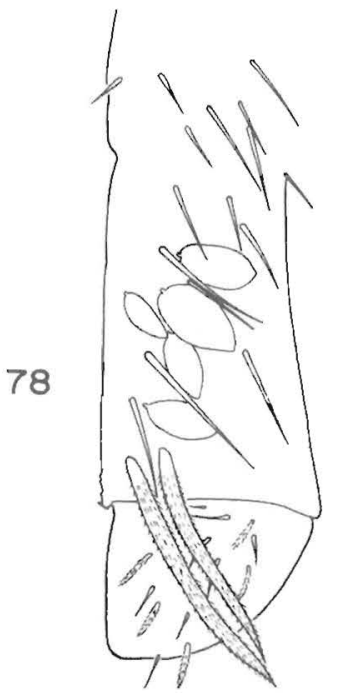

PlATE XI (Fig. 71-78).-D. litoreus. 71. Head macrochaetotaxy. 72. Labrum. 73. Outer labial papilla. 74. Body macrochaetotaxy. 75. Head of maxilla. 76. Maxillary palp. 77. Interocular chaetotaxy. 78. Anterior face of collophore. 


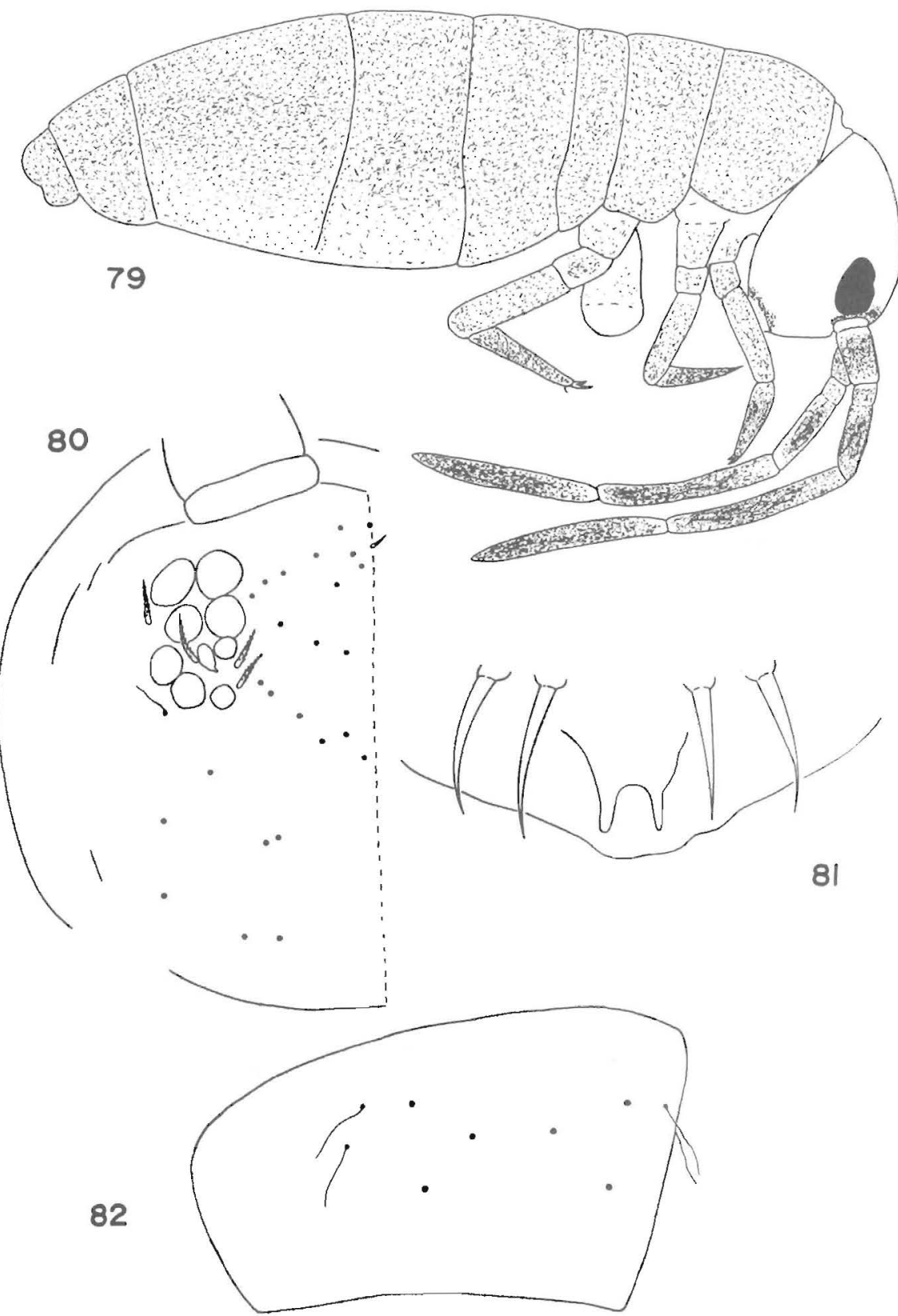

Plate XII (Fig. 79-82).-D. halophilus. 79. Distribution of blue pigment. 80. Head macrochaetotaxy. 81. Setae of third labral row and labral papillae. 82. Distribution of macrochaetae (dots) and bothriotricha on Abd. 4. 


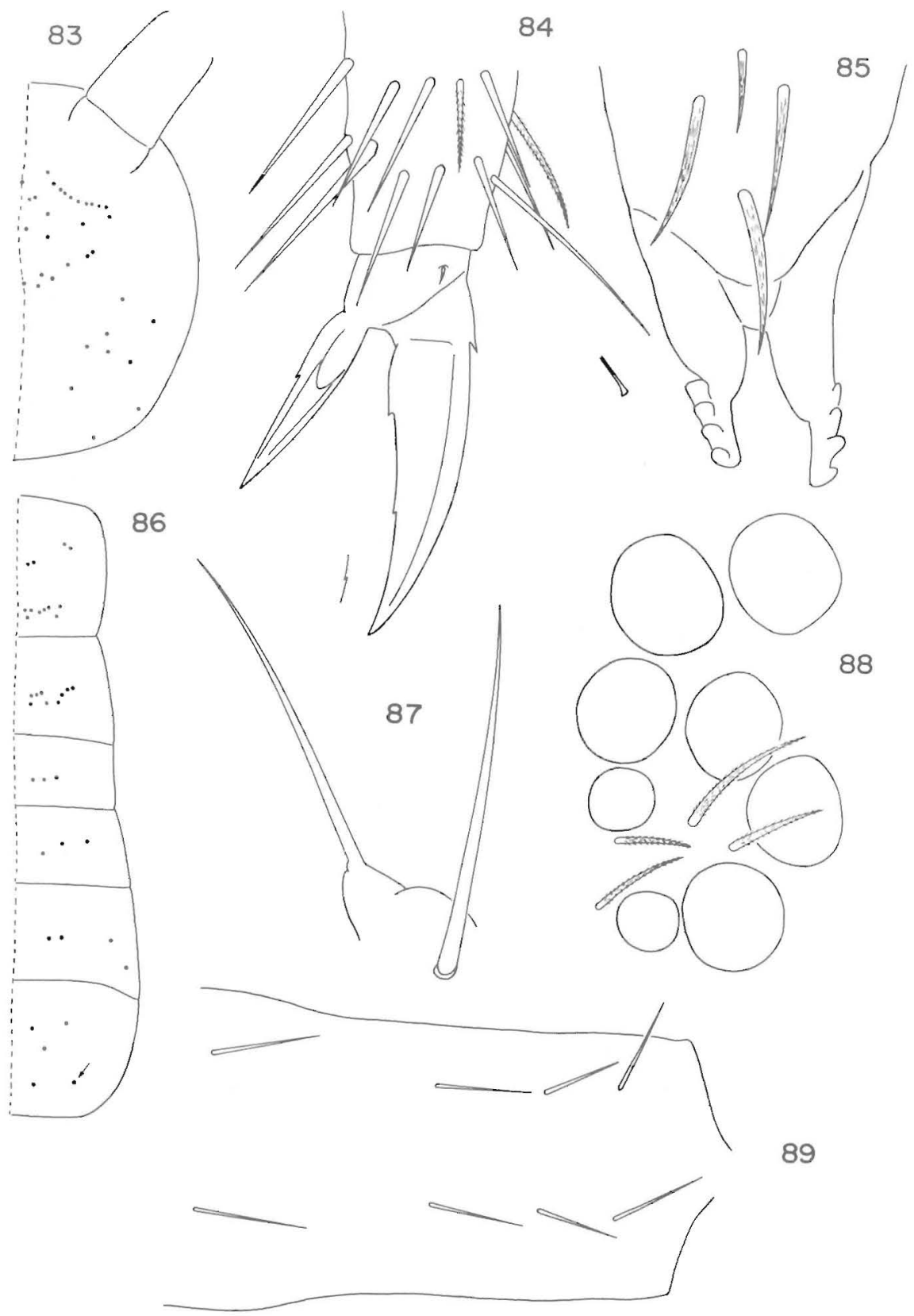

Plate XIII (Fig. 83-89).-D. gemellus. 83. Head macrochaetotaxy. 84. Metathoracic claws. 85. Tenaculum. 86. Body macrochaetotaxy. 87. Maxillary palp. 88. Interocular chaetotaxy. 89. Distribution of smooth setae on dorsum of manubrium. 
Trochanteral organ of $30-40$ basally thick setae. Inner margin of tibiotarsi with $15-20$ erect smooth setae arranged in 3-4 rows, outer margin of tibiotarsi with 1-2 similar setae in vicinity of tenent hair (fig. 51). Inner margin of unguis tridentate, unguiculus with outer tooth. Tenent hair lanceolate.

Body macrochaetotaxy as in figure 50. Tenaculum (fig. 52) with 6-7 setae. Dorsum of manubrium with scales and about 26 smooth erect setae not arranged in definite rows, more abundant proximally. Dental lobe with large macrochaeta-like seta, nearby a smooth seta. Inner margin of dentes with row of $16-25$ spines (fig. 55 ).

\section{Diagnosis}

This is the only species of the genus with dental spines and six macrochaetae on each side of Abd. 1. It is close to D. luzonensis described below but differs in the number of $\mathrm{P}$ macrochaetae, chaetotaxy of Th. 3 , Abd. 1 and Abd. 4, and shape of the subapical seta of the maxillary palp and of the larger head and body macrochaetae (normal in gapudi, bifurcated in luzonensis - fig. 61).

Dicranocentrus gapudi is also close to D. sundanensis Schött 1925 (Malaya and Sarawak), but they differ at least in the number and distribution of dental spines and the chaetotaxy of Abds. 1, 3 and 4.

\section{Comments}

The species is named after Dr. Victor P. Gapud, in recognition of his pioneering studies of Philippine Collembola.

\section{Material examined}

Philippine Islands, Mindoro, Puerto Galera, near St. Theodoro cascade, leaf litter, 2-4.i.1979, L. Deharveng, holotype and 4 paratypes (3 on slides). As preceding but collected at the seashore, 2 paratypes on slides. As in the first locality, but collected near $300 \mathrm{~m}$ between 2729.xii.1979, 2 paratypes in alcohol.

\section{Dicranocentrus luzonensis NEW SPECIES}

Maximum length $2.8 \mathrm{~mm}$. Distribution of violet pigment as in $D$. indecisus. Ratio length of antennae/length of specimen $=0.6$, antenna/ length of head $=3.6$, Ant. 6/Ant. $5=0.38$. Apex of Ant. 6 without pin seta, with 2 large apically broad setae (fig. 60). Largest head and body macrochaetae apically bifurcated (fig. 61).

Head macrochaetotaxy, interocular chaetotaxy, labral papillae (fig. 58), differentiated seta of outer labial papilla, and ventral head chaetotaxy as in D. gapudi except for absence of $3 \mathrm{P}$ setae (fig. 49). Subapical seta of maxillary palp somewhat thicker than apical seta (fig. 62). Posterior 
labial row internal to seta e with 5-7 smooth and 0-3 ciliated setae, $1_{1}$ and $1_{2}$ smooth. Behind postlabial quadrangle, near posterior margin of head, 3-7 lightly ciliated setae on both sides of median groove.

Trochanteral organ of 24-37 basally thick setae. Number and arrangement of tibiotarsal smooth setae as in $D$. gapudi. Inner margin of unguis only with basal pair of teeth or in addition 1-2 unpaired teeth. Unguiculus with outer tooth and variable number of small denticles on inner lamellae (fig. 56, 57). Tenent hair lanceolate.

Body macrochaetotaxy as in Fig. 59. Tenaculum with 5-7 setae. Dorsum of manubrium with scales and double row of $5+5$ or $6+6$ smooth setae (fig. 63). Dental lobe with short macrochaeta-like seta, nearby 1-3 (usually 2) smooth setae. Inner margin of dentes with row of 14-20 spines arranged as in D. gapudi.

\section{Diagnosis}

This is the only Asiatic species with dental spines and three macrochaetae on each side of Abd. 1 . It is close to D. gapudi and the latter's diagnosis lists the differences between the two.

\section{Comments}

All the specimens from Mount Data Lodge have bidentate ungues; those from Baguio have tridentate ungues and in some legs a second unpaired tooth. No other differences were detected between these populations.

\section{Material examined}

Philippine Islands, Luzon, Baguio, near Crystal Caves, 1,500 m, humid litter under pines, 1-2.i.1980, L. Deharveng, holotype and 6 paratypes (2 on slides). Luzon, Mountain Province, Mount Data Lodge, 2,200-2,300 $\mathrm{m}$, rotten tree trunk, 22-23.xii.1979, L. Deharveng, 10 paratypes (5 on slides).

\section{Dicranocentrus litoreus NEW SPECIES}

Maximum length $2.1 \mathrm{~mm}$. Distribution of violet pigment as in $D$. indecisus, background white to very light blue. One specimen with background brown and median unpigmented line from 'Th. 2 to And. 3. Ant. 6 missing, basal subdivision of Ant. 2 (Ant. 3) inconspicuous, Ant. 3 and Ant. 4 scaled.

Head macrochaetotaxy as in figure 71 . Interocular chaetotaxy of 1 outer and 3-4 inner setae (fig. 77, the small insertion probably belongs to a scale). Setae of third labral row considerably thicker than setae of other rows (fig. 72), margin of labrum with 2 indistinct papillae. Head of mandible elongated (fig. 65, 66), head of maxilla (fig. 75) unmodified. 
Setae of maxillary palp as in figure 76. Differentiated seta of outer labial papilla thick, placed far back on its papilla (fig. 73). Posterior labial row internal to seta e with 1 smooth and $5-7$ ciliated setae; $L_{1}$ ciliated, $1_{2}$ smooth or ciliated (ciliated on 1 side of 1 specimen). Behind postlabial quadrangle, near posterior margin of head, 2 ciliated setae placed as in D. reunionensis (fig. 19). Parallel to posterior margin of labium $2+2$ smooth setae, all other setae of venter of head, including postlabial quadrangle, ciliated.

Trochanteral organ of 27-32 thick, somewhat spiniform, setae. Inner margin of tibiotarsi without smooth setae, with several thick ciliated setae. Unguis (fig. 64, 67) short and thick, inner margin bidentate. Unguiculus thick, with outer tooth and an inner projection caused by fusion of 2 lamellae. Tenent hair very long, clavate.

Body macrochaetotaxy as in figure 74. Anterior face of collophore (fig. 78) with usual $2+2$ terminal setae but these are much thicker. Tenaculum with 1-2 setae. Dorsum of manubrium without scales or smooth setae; largest ciliated setae with sharply pointed tip (fig. 68), similar setae on dorsum of dentes. Dental lobe with large S-shaped seta (fig. 69), no smooth setae or spines on dentes. Mucro slightly elongated, without basal spine (fig. 70).

\section{Diagnosis and comments}

Specimens of this species, and of $D$. halophilus n. sp. described below, are unusual on several accounts (the differences between the two are given in the latter's description). The unique claw structure suggests that both are adapted for life in the littoral zone, where they are probably submerged by the tides. Other features unique to these species are the elongated head of the mandible (fig. 66), enlarged setae of third labral row (cf. fig. 58, 72), large S-shaped seta on the dental lobe, apically sharply pointed ciliated setae of the furcula, absence of mucronal spine, and the reduced head and body chaetotaxy. The basal subsegment of Ant. 2 is inconspicuous but this also occurs in D. pilosus (Mari Mutt and Bhattacharjee 1980: 167, fig. 30).

The only species of the genus with somewhat similar head and body chaetotaxy is D. singularis Mari Mutt and Bhattacharjee (op. cit.) known from northeast India. This species also lacks head macrochaeta $\mathrm{S}_{0}$ and its body chaetotaxy is reduced, but the setal patterns of Th. 3 to Abd. 1 are very different. The two "marine" species described in this paper are the only Dicranocentrus without macrochaetae on Abd. 1.

A most intriguing observation is that the head chaetotaxy of $D$. litoreus is practically identical to that of the members of Heteromurus s. str. (cf. Mari Mutt 1980: 49, fig. 28), and the body chaetotaxy of $D$. litoreus differs from that of all but one of the seven species of Heteromurus s. 
str. by the presence of a single extra macrochaeta on Th. 3 (cf. Mari Mutt 1980: 45, fig. 5). Whether such similarity between otherwise distinct species with very different geographic distribution and habitats indicates evolutionary affinity or convergence remains conjectural.

I have found three differences between the pro- and metathoracic legs (fig. 64, 67). In the former, the inner ungual teeth are smaller and more basal, the pretarsal setae are similar in size and position, and the outer unguicular tooth is smaller. Mesothoracic claws are intermediate, their pretarsal setae are equal in length but are not completely opposite each other.

\section{Material examined}

Philippine Islands, Mindoro, Puerto Galera, on the beach, 2729.xii.1979, L. Deharveng, holotype and 4 paratypes (2 on slides). As preceding but collected at the seashore between $2-4$.i.1979, 3 paratypes ( 2 on slides).

It should be noted that three specimens of $D$. gapudi were collected together with this species in January 1979. The former species was also collected in forest leaf litter and presents no modifications for life in the littoral habitat.

\section{Dicranocentrus halophilus NEW SPECIES}

This species is very similar to the preceding but the following characters distinguish them. Maximum length $2.3 \mathrm{~mm}$. Body, collophore, manubrium and legs uniformly light blue to light violet, pigment darker on tibiotarsi (fig. 79). Pigment on head restricted to eye patch and band near antennal bases, antennae violet. Ratio length of antennae/length of specimen $=0.54$; antenna/length of head $=2.6$; Ant. $6 /$ Ant. $5=1.1$ Apex of Ant. 6 without pin seta or unusually long smooth setae. Ant. 3 and Ant. 4 without scales. Seven P macrochaetae present (fig. 80). Interocular chaetotaxy of 1 outer seta, 3 inner setae and a scale (one specimen has a small seta in place of the scale). Margin of labrum with 2 distinct papillae (fig. 81). Posterior labial row internal to seta e with $0-1$ smooth and 2-5 ciliated setae. Behind postlabial quadrangle, near posterior margin of head, 1-3 ciliated setae. Abd. 4 with 3 macrochaetae (fig. 82).

The most reliable differences between this species and $D$. litoreus are the pigmentation, degree of development of the labral papillae, number of $\mathrm{P}$ macrochaetae, and the number of macrochaetae on Abd. 4.

\section{Material examined}

Papua New Guinea, Lae, tide debris near the bridge, 11.xii.1978, L. Deharveng, holotype and 9 paratypes (4 on slides). 


\section{Dicranocentrus gemellus NEW SPECIES}

Maximum length $2.3 \mathrm{~mm}$. Pigmentation as in D. indecisus (specimen from New Britain) or head and body covered more or less uniformly by violet pigment; legs and antennae intensely pigmented, furcula pigmented to dentes. Collophore pigmented (specimens from New Guinea). Ant. 6 missing.

Head macrochaetotaxy as in figure 83. Interocular chaetotaxy (fig. 88) of 1 anterior seta and 3-4 inner setae. Labral papillae hooklike. Setae of maxillary palp (fig. 87) similar in length and shape. Differentiated seta of outer labial papilla as in $D$. thaicus. Posterior labial row internal to seta e with 7-8 smooth setae, no ciliated setae or scales; $1_{1}$ and $1_{2}$ smooth. Behind postlabial quadrangle, near posterior margin of head, 2-3 finely ciliated setae. Setae of anterior ventral half of head smooth, towards posterior margin of head becoming very finely ciliated.

Trochanteral organ of 30-36 basally thick setae. Tibiotarsi with many smooth setae on all its sides, distally on segment at least $3 \times$ more abundant than ciliated setae. Inner margin of unguis tri- or quadridentate (fig. 84). Unguiculus with very small outer tooth, apparently absent in some legs. Tenent hair lanceolate or clavate.

Body macrochaetotaxy as in Fig. 86. Tenaculum (fig. 85) with 3-4 setae. Dorsum of manubrium without scales but with $3+3$ or $4+4$ smooth setae in double row (fig. 89). Dental lobe with macrochaeta-like seta and nearby at least 1 smooth seta. Dental spines absent.

\section{Diagnosis}

The only significant difference between this species and $D$. solomonensis Mari Mutt 1979 (Solomon Islands) is the chaetotaxy of Th. 3. The new species has a proximal group of $1+3+1$ macrochaetae, whereas in D. solomonensis the arrangement is $2+3+2$. This difference may seem trivial but setal patterns in this segment are constant. I have verified the chaetotaxy of 16 paratypes of $D$. solomonensis from the islands of Guadalcanal, Choiseul, Santa Isabel and Kolombangara, and 1 specimen from Vella Lavella (Pusisoma, Berlese funnel, 29.xi. 1963, P. Shanahan) found in the present collection.

\section{Material examined}

Papua New Guinea, Finschaffen, leaf litter, 16-20.xii.1978, L. Deharveng, holotype and 1 paratype on slides. New Britain, Pomio, at sea level, sieved forest soil, 10.vii.1979, J. D. Bourne, 1 paratype dissected and parts mounted on three slides. 


\section{RESUMEN}

Se describen ocho especies nuevas de Dicranocentrus: capitaneus (Perú), reunionensis (Isla Reunión), indecisus (Nepal); gapudi, luzonensis y litoreus (Filipinas); halophilus y gemellus (Papua Nueva Guinea). Se redescriben las especies $D$. thaicus Yosii y D. pilosus Mari Mutt. Dicranocentrus litoreus y $D$. halophilus se recolectaron en playas y presentan varias modificaciones que pueden ser adaptaciones a la zona litoral: uñas gruesas y cortas, mandíbulas alargadas, sedas labrales gruesas y pérdida de la espina del mucrón. Estas dos especies presentan una quetotaxia cefálica y corporal reducida y muy similar a la de las especies de Heteromurus s. str. Ochenta y nueve figuras complementan las descripciones.

\section{LITERATURE CITED}

1. Christiansen, K. and P. Bellinger, 1980. The Collembola of North America north of the Rio Grande. Part 3, Family Entomobryidae. Grinnell College, Grinnell, Iowa, p. $785-1042$.

2. Jacquemart, S., 1980. Collemboles nouveaux du Perou. Bull. Inst. R. Nat. Belg. Entomol. 52 (15): 1-27.

3. Mari Mutt, J. A., 1979. A revision of the genus Dicranocentrus Schött (Insecta: Collembola: Entomobryidae). Univ. P. R. Agric. Exp. Stn. Bull. 259, 79 pp.

4. - 1980. A revision of Heteromurus s. str. (Insecta: Collembola: Entomobryidae). Trans. Ill. State Acad. Sci. 72 (3): 29-50.

5. - 1981a. New genus, a new species, and complements to the descriptions of seven Neotropical Dicranocentrus (Collembola: Entomobryidae: Orchesellinae). J. Agric. Univ. P. R. 65 (2): 90-107.

6. - 1981b. Two new Dicranocentrus from Nepal and a key to the Indian and Nepalese species (Collembola: Entomobryidae). Pan-Pac. Entomol. 57 (4): 493-99.

7. - and R. K. Bhattacharjee, 1980. Four new species of Dicranocentrus from northeast India and Nepal (Collembola: Entomobryidae: Orchesellinae). Pac. Insects. 22 (1-2): 162-70.

8. Prabhoo, N. R., 1971. Soil and litter Collembola of South India, I. Arthropleona. Orient. Insects. 5 (1): 1-46.

9. Salmon, J. T., 1964. An index to the Collembola. Roy. Soc. N. Z. Bull. 7, 651 pp.

10. Schött, H. G., 1925. Collembola from Mt. Murud and Mt. Dulit in northern Sarawak, Sarawak Mus. J. 8: 107-27.

11. Yosii, R., 1961. On some Collembola from Thailand, Nature and Life in Southeast. Asia, 1: 171-98. 